\title{
Post-traumatic pancreatic pseudocyst - case presentation with review of literature
}

\author{
Pseudochistul pancreatic posttraumatic-prezentare de caz şi review al \\ literaturii
}

\author{
Ștefania MANOLESCU ${ }^{1}$, Ramona ILIESCU ${ }^{1}$, Mihnea AVRAM ${ }^{1}$, Sorin PĂUN ${ }^{1,2}$, \\ Mircea BEURAN ${ }^{1,2}$, Ruxandra AVRAM ${ }^{1}$, Alexandru Laurențiu CHIOTOROIU ${ }^{1}$, \\ Bogdan GASPAR ${ }^{1,2}$ \\ ${ }^{1}$ Spitalul Clinic de Urgență, Bucureşti, România \\ ${ }^{2}$ Universitatea de Medicină şi Farmacie „Carol Davila“, Bucureşti, România
}

\begin{abstract}
Pancreatic trauma remains an enigma of diagnosis and treatment even in the era of modern medicine, in which there are advanced technological and diagnostic means. The pancreas pseudocyst is one of the most common complications of acute and chronic pancreatitis and pancreas trauma, but rarely occurs following trauma. The diagnosis and treatment of post-traumatic pancreatic pseudocyst have recently benefited from the new diagnostic and treatment imaging techniques that have changed the therapeutic attitude in the pancreatic pseudocyst.
\end{abstract}

Keywords: post-traumatic pancreatic pseudocyst, abdominal trauma, pancreatic trauma

\section{REZUMAT}

Traumatismul pancreatic rămâne o enigmă de diagnostic şi tratament chiar și în era medicinei moderne, în care există mijloace tehnologice şi de diagnostic avansate. Pseudochistul de pancreas este una dintre cele mai frecvente complicații ale pancreatitei acute şi cronice şi ale traumatismelor la nivelul pancreasului, însă apare rareori în urma traumatismului. Diagnosticul şi tratamentul pseudochistului pancreatic posttraumatic au beneficiat în ultimul timp de aportul noilor tehnici imagistice de diagnostic şi tratament, cee ce a modificat atitudinea terapeutică în pseudochistul pancreatic.

Cuvinte cheie: pseudochist pancreatic posttraumatic, traumatism abdominal, traumatism pancreatic

\section{INTRODUCERE}

Traumatismele la nivelul pancreasului constituie $2 \%$ dintre toate leziunile abdominale. 0 treime dintre leziunile pancreatice se datorează traumatismelor, însă incidența poate crește odată cu aplicarea legilor obligatorii ale centurii de siguranță. Rata ridicată a mortalității raportate $(20-40 \%)$ se datorează faptului că este necesară o forță consi- derabilă pentru a deteriora pancreasul, iar această forță afectează adesea alte organe, în principal ficat, splină, mezenter sau torace. Complicații incluzând abcesul pancreatic, fistulele, hemoragia sau pseudochistul se dezvoltă la o treime dintre cei care supraviețuiesc $(1,2,3)$. Pseudochistul pancreatic este o colecție localizată de secreții pancreatice lipsite de membrana epitelială ca urmare a inflamației pancreatice sau a tulburării ductale. 
Traumatismul reprezintă un factor etiologic în 3-8\% dintre cazurile de adulți, dar este responsabil pentru aproape toate pseudochisturile pancreatice pediatrice (1-3).

Tradițional, colecțiile pancreatice sunt tratate prin debridare și drenare, cu o mortalitate de la $10 \%$ până la $59 \%$ și o morbiditate de la $60 \%$ până la $93 \%$. Drenarea colecțiilor pancreatice prin ghidaj ecografic și CT sunt recomandate ca ultime tehnici invazive, dar ele necesită un drenaj extern pentru o perioadă extinsă de timp, cu formarea unei fistule pancreatice în mai mult de 39\% dintre cazuri, după datele materialelor publicate. Un alt acces minimum invaziv este constituit de debridarea retroperitoneală a colecțiilor pancreatice. Majoritatea autorilor pledează pentru accesul endoscopic în pseudochisturile pancreatice necomplicate și în abcese (6-14).

\section{CAZ CLINIC}

În cele ce urmează, vă prezentăm un caz clinic al unui pacient de sex masculin, din mediul urban, normal dezvoltat staturo-ponderal, cunoscut cu hepatită virală cronică cu virus B și pancreatită acută necrotico-hemoragică posttraumatică recentă în urma unui traumatism abdominal cu disjuncție cefalo-corporeală. Pacientul a suportat o intervenție chirurgicală în care s-au efectuat: necrectomie pancreatică, colecistectomie și nefrectomie dreaptă. Evoluția a fost marcată de apariția unei fistule pancreatice pentru care s-a montat un drenaj percutan în flancul drept până în spațiul pancreatico-gastric, moment în care se transferă la Spitalul Clinic de Urgență pentru evaluare endoscopică și continuarea tratamentului de specialitate.

La internare pacientul prezintă stare generală medie, conștient, cooperant, echilibrat hemodinamic (TA = 100/60 mmHg, AV = 75 bpm) și respirator, tegumente și mucoase colorate constituțional, abdomen suplu mobil cu respirația, sensibil la palpare la nivelul epigastrului, fără semne de iritație peritoneală, fără formațiuni abdominale decelabile la palpare, cu cicatrice mediană abdominală postchirurgicală vindecată, tub de dren existent în flancul drept, tranzit intestinal prezent, diureză normocromă. Biologic la internare: lipază 3.000 U/I, în rest fără alte modificări.

Se efectuează papilosfincterotomie endoscopică retrogradă (ERCP), care decelează papila duodenală de aspect normal. Se vizualizează un diverticul de 1/1/1 cm, situat înalt parapapilar, după care se canulează cu sfincterotom pe ghid, se realizează colangiograma, cu vizualizarea unui coledoc de aspect normal. Se redirecționează canulotomul și ghidul în direcția pancreasului și se inseră contrast pe canalul Wirsung, care are un diametru de $2 \mathrm{~mm}$, dar cu amputare distală la 3-4 cm de orificiul papilar. Se încearcă depașirea stenozei pe ghid, dar nu se reușește (Figura 1).

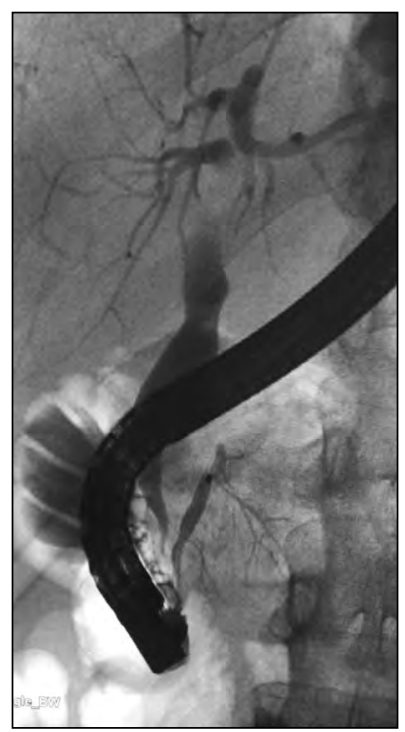

FIGURA 1. Imagine ERCP. CST retrogradă. Colangiowirsungografie retrogradă. Sfincterectomie biliară și pancreatică. Stop total la nivelul Wirsungului cefalo-corporeal

La aproximativ 4 luni de la controlul anterior, se repetă ERCP și se angajează canula pe tubul de dren, care avansează până la capătul proximal, se injectează contrast care nu avansează dincolo de capătul proximal. Se poziționează duodenoscopul în fața unei papile cu sfincterectomie anterioară. Se canulează selectiv coledocul și se injectează substanță de contrast, care evidențiază cale biliară distală efilată, cale biliară (CBP) proximală $10 \mathrm{~mm}$. Se canulează Wirsung-ul, care are o conformație efilată, cu ducte laterale minore vizibile, și se încearcă în multiple rânduri avansarea ghidului sau a canulei dincolo de amputarea ce probabil se situează mediocefalic - însă fără succes. Concluzii: CST anterioară, tub de dren pancreatic în situ, colangiogramă - CBP efilată distal și ușor dilatată proximal, Wirsungogramă: canulare eșuată a ductului Wirsung proximal (Figura 2).

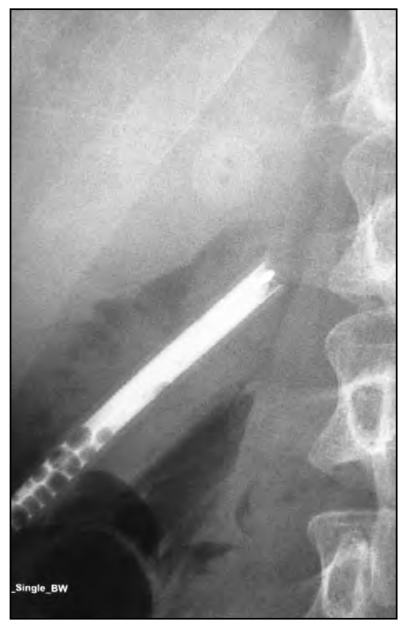

FIGURA 2. Imagine ERCP - control 
Ecografia efectuată ne-a arătat: tub de dren cu capătul proximal la nivelul bursei omentale, duct Wirsung de $3 \mathrm{~mm}$, moment în care s-a decis efectuarea unei ecoendoscopii ce a relevat: duct Wirsung de $4 \mathrm{~mm}$, cu posibilă zonă de întrerupere la nivelul procesului uncinat.

În urma investigațiilor efectuate, s-a decis suprimarea tubului de dren în vederea facilitării formării unei colecții pentru drenaj.

Ulterior, la aproximativ 4 săptămâni, se efectuează ecografie abdominală ce decelează colecție peripancreatică de 50/35 mm, cu Wirsung de 4 $\mathrm{mm}$ (Figura 3).

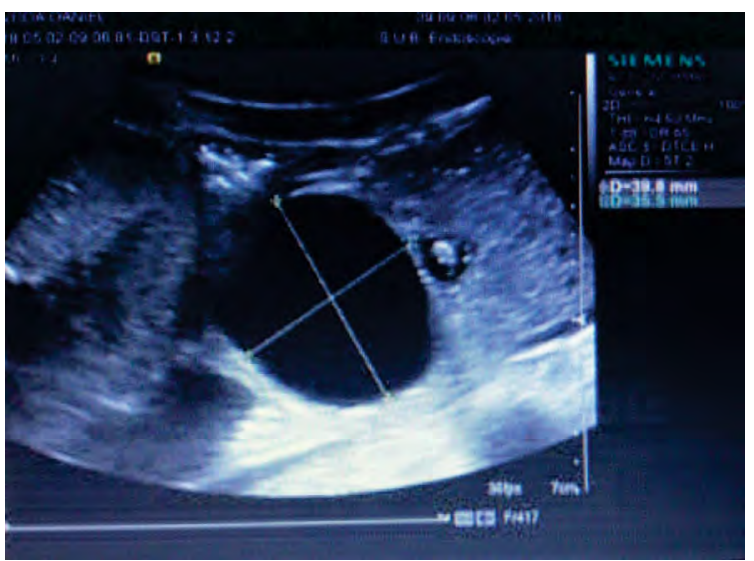

FIGURA 3. Imagine efectuată la ecografia abdominală după suprimarea tubului de dren

După formarea colecției se repetă ecoendoscopia. Se introduce ecoendoscopul până la nivelul D II, duct Wirsung $4 \mathrm{~mm}$ cu zona de întrerupere la nivelul procesului uncinat. Peripancreatic, colecție de 50/35 mm, ce se puncționează și se drenează. Se montează hemoclip pentru acoperirea defectului parietal. Concluzii: Colecție peripancreatică drenaj prin stent dublu pig tail ghidat ecoendoscopic (Figurile 4,5,6).

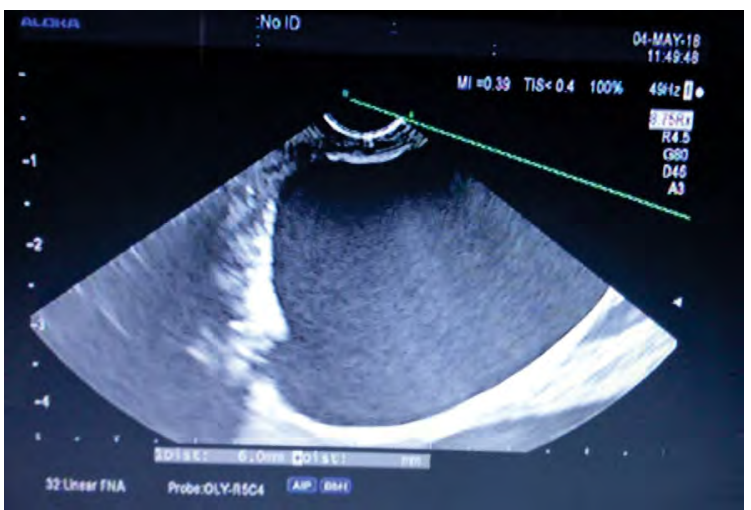

FIGURA 4. Imagine ecoendoscopie

Evoluția pacientului a fost favorabilă sub tratament antialgic și reechilibrare hidroelectrolitică.
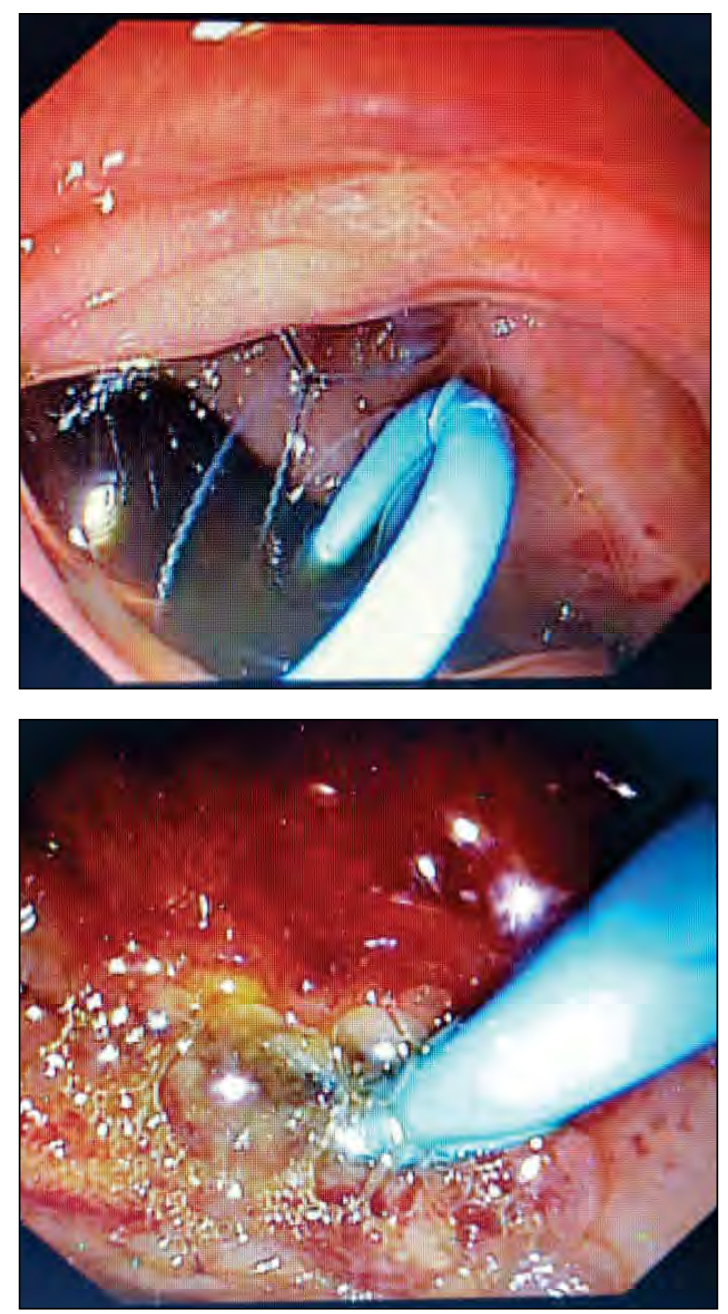

FIGURA 5. Drenajul colecției prepancreatice prin montare de stent transgastric pigtail 7Fr

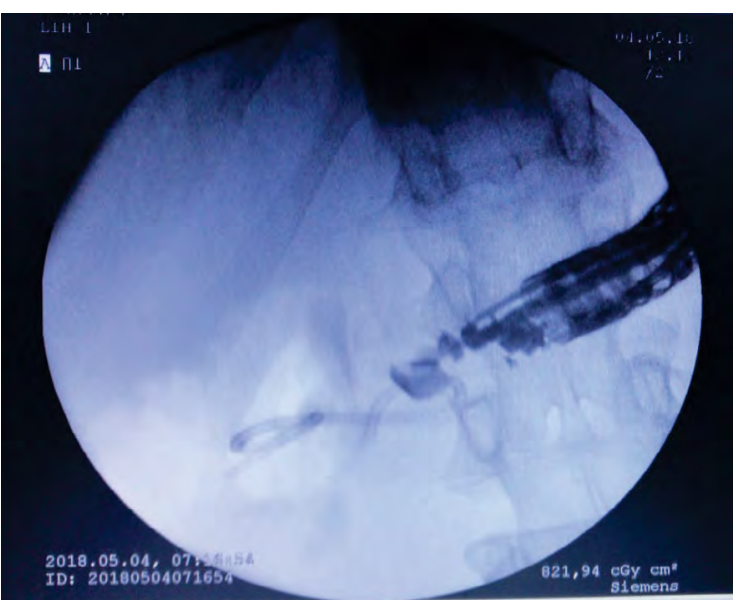

FIGURA 6. Stentul dublu pigtail şi ecoendoscopie sub ecran fluoroscopic

Pacientul s-a externat cu recomandare de control la 30 de zile.

Particularitatea cazului este aceea că s-a efectuat intervenție chirurgicală pentru leziunea pancreatică posttraumatică primară, iar ulterior s-a efectuat drenaj transgastric ecoendoscopic. 


\section{DISCUȚII}

Leziunile pancreatice datorate traumatismului abdominal sunt de obicei tratate chirurgical și există o experiență limitată de endoterapie pancreatică în tratamentul acestor pacienți. Întrucât integritatea ductului pancreatic principal este cel mai important determinant al morbidității și mortalității în leziunile pancreatice, ERCP a fost utilizată în principal pentru imagistica detaliată a ductului pancreatic, pentru a defini natura și localizarea leziunii ductale, astfel încât să se poată administra un tratament chirurgical adecvat (1-5).

Există o experiență limitată a ERCP terapeutică în astfel de situații, probabil din cauza logisticii efectuării ERCP terapeutice în centrele specializate pentru traumatisme și a problemelor tehnice ce apar în efectuarea ERCP la un pacient politraumatizat. Cu toate acestea, în acest caz am arătat că leziunea pancreatică cauzată de traumatismul abdominal poate fi tratată cu succes și în condiții de siguranță combinând tratamentul chirurgical cu terapia endoscopică (15-18).

De asemenea, s-a demonstrat că drenajul endoscopic transpapilar este util în gestionarea pacienților cu leziuni pancreatice ca urmare a traumatismelor abdominale (1). Acesta fost utilizat pentru tratarea leziunilor ductale pancreatice atât în faza timpurie a traumatismului pancreatic, cât și mai târziu, pentru a gestiona complicațiile leziunii ductale. Kim și colab. au studiat 14 pacienți cu leziune de canal pancreatic posttraumatic, pe ERCP au existat scurgeri de substanță de contrast din ductul pancreatic principal în cavitatea peritoneală la opt dintre pacienți, scurgeri localizate în parenchimul pancreatic la trei pacienți și opacifiere parenchimatoasă printr-un duct ramificat lezat la trei pacienți $(28,29)$. Pacienții cu scurgere liberă a contrastului în peritoneu au fost tratați prin intervenție chirurgicală, iar cei cu scurgeri din ductul pancreatic principal limitat la parenchimul pancreatic au fost tratați prin plasarea unui stent pancreatic transpapilar 7Fr în 24-96 ore de la rănire (22-27).

\section{CONCLUZII}

Leziunea pancreatică posttraumatică poate fi tratată atât chirurgical, cât și endoscopic, inclusiv la pacienții cu lezarea completă a ductului pancreatic principal.

Tratamentul pseudochistului pancreatic posttraumatic trebuie abordat într-un mod multidisciplinar. Procedura trebuie evaluată în funcție de experiența fiecărui centru și/sau de posibilitatea de a trimite pacientul la un centru mai experimentat.

Conflict of interest: none declared Financial support: none declared

\section{BIBLIOGRAFIE}

1. Bhasin DK, Rana SS, Rawal P. Endoscopic retrograde pancreatography in pancreatic trauma: Need to break the mental barrier. J Gastroenterol Hepatol 2009; May; 24(5):720-8.

2. Jurkovich GJ, Carrico CJ. Pancreatic trauma. Surg Clin. North Am. 1990; 238-56.

3. Subramanian A, Dente CJ, Feliciano DV. The management of pancreatic trauma in the modern era. Surg. Clin. North Am. 2007; Dec; 87(6):1515-32.

4. Patton JH, Fabian TC. Complex pancreatic injuries. Surg. Clin. North Am. 1996; 76: 783-95.

5. Degiannis E, Glapa M, Loukogeorgakis SP, Smith MD. Management of pancreatic trauma. Injury 2008; Jan;39(1):21-9.

6. Telford JJ, Farrel JJ, Saltzman JR, Shields SJ, Banks PA, Lichtenstein DR, Johannes RS, Kelsey PB, Carr-Locke DL. Pancreatic stent placement for duct disruption. Gastrointest. Endosc. 2002; Jul;56(1):18-24.

7. Varadarajulu S, Noone TC, Tutuian R, Hawes RH, Cotton PB. Predictors of outcome in pancreatic duct disruption managed by endoscopic transpapillary stent placement. Gastrointest. Endosc.2005; Apr;61(4):568-75.
8. Bhasin DK, Rana SS, Udawat HP, Thapa BR, Sinha SK, Nagi B. Management of multiple and large pancreatic pseudocysts by endoscopic transpapillary nasopancreatic drainage alone. Am. J. Gastroenterol. 2006; Aug; 101(8):1780-6.

9. Bhasin DK, Rana SS, Siyad I, Poddar U, Thapa BR, Sinha SK, Nagi B. Endoscopic transpapillary nasopancreatic drainage alone to treat pancreatic ascites and pleural effusion. J. Gastroenterol. Hepatol. 2006; Jun; 21(6):1059-64.

10. Saeed ZA, Ramirez FC, Hepps KS. Endoscopic stent placement for internal and external pancreatic fistulas. Gastroenterology 1993; Oct;105(4):1213-7.

11. Costamagna $G$, Mutignani $M$, Ingrosso $M$, Vamvakousis V, Alevras P, Manta R, Perri V. Endoscopic treatment of post-surgical external pancreatic fistulas. Endoscopy 2001; Apr;33(4):317-22.

12. Bhasin DK, Rana SS, Nanda M, Chandail VS, Masoodi I, Kang M, Kalra N, Sinha SK, Nagi B, Singh K. Endoscopic management of JOP. J Pancreas (Online) 2012 Mar 10; 13(2):187-192.

13. Bhasin DK, Rana SS, Nanda M, Chandail VS, Gupta R, Kang M, Nagi B, Sinha SK,
Singh K. Comparative Evaluation of Transpapillary Drainage with Nasopancreatic Drain and Stent in Patients with Large Pseudocysts Located Near Tail of Pancreas. J Gastrointest Surg. 2011 May;15(5):772-6.

14. Rana SS, Bhasin DK, Nanda M, Siyad I, Gupta R, Kang M, Nagi B, Singh K. Endoscopic transpapillary drainage for external fistulas developing after surgical or radiological pancreatic interventions. $J$ Gastroenterol Hepatol. 2010 Jun; 25(6):1087-92.

15. Carr-Locke DL, Gregg JA. Endoscopic manometry of pancreatic and biliary sphincter zones in man: Basal results in healthy volunteers. Dig. Dis. Sci. 1981; Jan; 26(1):7-15.

16. Sharma SS, Maharshi S. Endoscopic management of pancreatic pseudocyst in children - a long-term follow-up. J. Pediatr. Surg. 2008; Sep;43(9):1636-9.

17. Stermer E, Zeina AR, Rainis T, Goldstein O, Keren D, Lavy A. Traumatic pancreatic transection treated endoscopically. Injury Extra 2007; 38: 384-6.

18. Kimble RM, Cohen RL, Williams S. Successful endoscopic drainage of a post 
traumatic pancreatic pseudocyst in a child. J.Pediatr. Surg. 1999.

19. Varadarajulu S, Wilcox CM, Tamhane A, Eloubeidi MA, Blakely J, Canon CL. Role of EUS în drainage of peripancreatic fluid collections not amenable for endoscopic transmural drainage. Gastrointest. Endosc. 2007; Dec;66(6):1120-2.

20. Kim HS, Lee DK, Kim IW, Baik SK, Kwon SO, Park JW, Cho NC, Rhoe BS. The role of endoscopic retrograde pancreatography in the treatment of traumatic pancreatic duct injury. Gastrointest. Endosc. 2001; 54: 49-55.

21. Houben $\mathrm{CH}$, Ade-Ajayi N, Patel S, Kane $\mathrm{P}$, Karani J, Devlin J, Harrison P, Davenport M. Traumatic pancreatic duct injury in children: Minimally invasive approach to management. J. Pediatr. Surg. 2007; Apr; 42(4):629-35.
22. Cattaneo SM, Sedlack JD, Kalloo AN, Lillemoe KD. Management of a pancreatic duct injury with an endoscopically placed stent. Surgery 2004; Jun;135(6):690-2.

23. Hsieh CH, Liu NJ, Chen RJ, Fang JF, Lin BC. Endoscopically placed pancreatic stent in a patient with concomitant two locations of main pancreatic duct disruption following pancreatic trauma. Hepatogastroenterology 2003; Jan-Feb;50(49):269-71.

24. Hashimoto A, Fuke H, Shimizu A, Nakano T, Shiraki K. Treatment of traumatic pancreatic duct disruption with an endoscopic stent. Pancreas 2003; Apr;26(3):308-10.

25. Bagci S, Tuzun A, Erdil A, Uygun A, Gulsen M, Dagalp K. Endoscopic treatment of pancreatic duct disruption due to blunt abdominal trauma: A case report. Mil. Med. 2007; May;172(5):548-50.
26. Fabre JM, Bauret P, Prudhomme M, Quenet F, Noel P, Baumel H, Michel H, Domerque J. Posttraumatic pancreatic fistula cured by endoprosthesis in the pancreatic duct. Am. J. Gastroenterol. 1995; May;90(5):804-6.

27. Canty TG Sr, Weinman D. Treatment of pancreatic duct disruption in children by an endoscopically placed stent. J. Pediatr. Surg. 2001; Feb;36(2):345-8.

28. Lin BC, Chen RJ, Fang JF, Hsu YP, Kao YC, Kao JL. Management of blunt major pancreatic injury. J. Trauma 2004; Apr; 56(4):774-8.

29. Lin BC, Liu NJ, Fang JF, Kao YC. Long-term results of endoscopic stent in the management of blunt major pancreatic duct injury. Surg. Endosc. 2006; Oct; 20(10):1551-5. 